\title{
The Impact Factor of Education on the Public Sector - The Case of the U.S.
}

\author{
Constantinos Challoumis ${ }^{\dagger}$ \\ N.K.U.A. (National Kapodistrian University of Athens), Greece
}

\begin{tabular}{l}
\hline ARTICLE INFO \\
\hline Article History \\
Received 3 March 2020; \\
Accepted 28 May 2020 \\
\hline JEL Classifications \\
F6, F40, F43, F62, F63
\end{tabular}
ABSTRACT

\section{Purpose:}

To this thesis is analyzed the impact factor of education to the public sector and tax system, through a procedure of theoretical and mathematical analysis, a quantification method, an econometric method and behavioral scrutiny by a real case scenario. This work compares the cycle of money, to the one case using the impact factor of education and to the other case without it. Then, this work aims to study if the taxes for the education don't belong to the general approach that taxes make weaker the cycle of money, but have a positive effect on the economy, are a different case as the theory of the cycle of money provides.

Design/methodology/approach:

The analysis stands on the cycle of money and the impact factor of education. Therefore, the appropriate education to the economy supports the market and in general the economy. The impact factor of education enforces the economic dynamic of any economy. The study of cases when there is the factor of education and when this factor is omitted allows the extraction of the appropriate conclusions. Moreover, this analysis is used for the Q.E. method through R.B.Q. model. The use of simulations before the real application guarantees the significance of the results. To be able to understand the way that taxes for the education system, estimated to the one case how the economy interacts with these taxes and after this examination without these taxes, following the mathematical logic of the "reductio ad absurdum".

Finding:

The education of the U.S. for the period of 2012-2017 shows that taxes for education return to the economy, enhancing it. The general approach of simulation complies with this real

Keywords:

Education; Public Sector; U.S. Education; Theory of Cycle of Money; R.B.Q methodology; Q.E. method case scenario.

Research limitations/implications:

This paper shows that according to the theory of the cycle of money the education belongs to the case of factors that the taxes return to the economy, and robust the economic dynamic of a society.

Originality/value:

The findings of this study contribute to the existing knowledge regarding the concept of the cycle of money to the case of education. The taxes on education belong to the case that the money returns to the economy, on the contrary with most taxes that are not robust the economy and should be reduced.

\section{Introduction}

Definition of the cycle of money: The theory shows that to an economy the taxes return to the society, basically to the case of the education and the health system. But, the main rule is that the authorities should keep the taxes as low as it is this plausible. Moreover, if something is plausible to be offered by medium or small economic units, and enterprises, the government should protect them by very low taxes and the same time to put higher taxes on the bigger companies. But, for the case of the big companies that their purposes are not covered by small companies, should be put low taxes. Also,

${ }^{\dagger}$ Corresponding Author: CONSTANTINOS CHALLOUMIS

Email: challoumis_constantinos@yahoo.com

DOI: $10.25103 /$ ijbesar.131.07 
factories and high technology companies should have low taxes. Then, the main concept is to have an economy, with the best allocation of production. In that way, an economy achieves its higher level. Additionally, this theory shows that with the best allocation of production units and of taxes the money is cycled in the economy and is not lost from the economy, as it achieves the maximum use of the same amount of money in an economy. (Challoumis, The Theory of Cycle of Money 2018) (Challoumis, The Keynesian Theory and the Theory of Cycle of Money 2018) The cycle of money is based on the way that money reused in the economy and the way that is an economy is structured.

This paper has analyzed the case of the education, which belongs to the few cases that the taxes return directly back to the economy and serve the better allocation of its production units. The research problem is to clarify the effect of taxes on the education system to the economy, as according to the theory of the cycle of money the high rate taxes make weaker the economies. The taxes when applied to small and medium companies, to high technological units, and factories, should be low, but to companies that make controlled transactions, and large companies that substitute the activities of smaller companies the taxes should be higher than the other companies. Because the large companies and the companies that proceed to international controlled transactions, make international bank savings and the money lost from the local bank systems and the local markets, making the reuse of money weaker. According to the theory of the cycle of money some taxes robust the economies, and that taxes are considered as exceptions. The education system, as the education system, belongs to that exception. To that work is examined the role of taxes of the education system to the economy. Then, the hypothesis is that the taxes of the education system have a positive impact on the economy.

This work aims to study the impact factor of education on the cycle of money through the view of taxes. The paper scrutinizes the case of the cycle of money with and without all the determined impact factors of the education. Then, to the one application is used the impact factor of the education and in the other case is not used, to be able to conclusions about the behavior of the model. Thus, using the Q.E. method extracted conclusions, about the importance of this impact factor in the economy. The impact factor of education is used for the case of administration of the public sector to the private sector and the returns of taxes to the market. Moreover, it should be noted that any other rewarding taxes (taxes those enhance the economy) are excluded from this study to estimate the utility of this factor, achieving with that way to isolate the searching problem and hypothesis (the taxes for the education, of robust the economy). Therefore, this work has analyzed the comparison between the cycle of money including and then excluding the impact factor of education. (Challoumis 2019) The analysis which followed is based on the R.B.Q. (Rational Behavioral and Quantified model). This means that initially, the paper starts with the theoretical concepts and the mathematical structure. Also, this paper achieved a behavioral approach using here real data from the United States educational system for the period between 2009 and 2015. (Challoumis, The R.B.Q. (Rational, Behavioral and Quantified) Model 2019) Finally, we are compiled virtual quantity data to confirm the compliance between the theoretical approaches with a real case study.

\section{Methodology}

The Q.E. method is used to this work, to determine the mathematical equations and the conditions of the model. The dependent variable is used for the determination of the behavior of the model. It should be noted that it is given an upper limit and a lower limit to the values of the independent variables. Therefore are used two facets to the application of the Q.E. method, which are:

- Behavior analysis: The analysis of the behavior of the model stands on the structural characteristics of each model accordingly, using a determined mathematical equation. To the equation are used some variables of the model, and after compilations are determined the behavior of the model. Then, some variable is excluded to determine again the behavior of the model. This happens to conclude how the model acts with and without a certain variable.

- Frequency analysis: The frequency analysis behavior analyses the number of appearances of a variable subject to other variables, concluding the impact that one independent variable has on other independent variable or variables.

Hence, the Q.E. method uses as index four basic steps. The steps are these:

- First step: Initially, it is set the hypothesis. The hypothesis determines the aims and the scope of each study. Moreover, the hypothesis is the key element of the reliability of a model.

- Second step: Forward, it is set the generator. The generator belongs to the hardcore of the Q.E. method. This means that the generator is the source of the Q.E. method, as at this stage produced random numbers which used according to fuzzy logic to determine the form of the model. Based on the results of this second step follows the next step. (Challoumis, Fuzzy Logic Concepts in Economics 2018) 
- Third step: It is about the conclusions. The conclusions are the final stage of the analysis, except the case that the scientist obtains that needed further modifications. To serve the readjustments to model is needed the next step, of the feedback.

- Fourth step: It is the case of the feedback and is about the repetitions and the adequate adjustments to the model. (Challoumis, Arm's Length Principle and Fix Length Principle Mathematical Approach 2018)

Through these four steps, the Q.E. method used for the examination study. Therefore, is used a theoretical background, a mathematical structure, econometric scrutiny, a quantity procedure, and a real case scenario for the importance of education on the GDP. Thus, there are three steps, the theoretical and mathematical background (rational step - step 1), the quantification analysis (quantity step - step 2), and the econometric scrutiny plus the real case scenario (behavioral step -step 3). Step 1 is revealed to the next section, where the theoretical and mathematical background is applied. To step 2 was run the compilation of the following variables: the $\alpha_{p}$ is about the enforcement savings, of citizens and small and medium-sized enterprises, the $\alpha_{t}$ is about the case that there are escaped savings and $\alpha_{\mathrm{n}} * \mathrm{~h}_{\mathrm{n}}$ symbolizes the impact of education on the economic system. The final and third step is about the repetitions made by programming to modify the model.

Then is followed the R.B.Q methodology, this means that as the first step defined the hypothesis, the theoretical, and the mathematical background. As the second step is to set a compilation of the equations (the tree steps that referred before) to clarify the behavior of the model. As the third step is to set the econometric procedure to conclude the appropriate conclusions for the hypothesis. Finally compared the result of programming compilation with the mathematical, theoretical, and econometric results to establish that comply between them.

\section{Literature Review}

The profits and losses are connected with the case of the taxes and therefore with the case of the taxes to the education system in the economy. Because of the controlled transactions, the tax avoidance of the large companies, and the international controlled transactions affect the taxing system, according to the existing theory (The theory of cycle of money). Then the case of taxes to the education system is an exception from the general taxes. Therefore, the behavior of the companies and the implied taxes from the authorities define the frame of this research. Some necessary theoretical background is presented. Then, the contracts of companies and the agreements of companies with the authorities are very important for their profits and losses. The changes in the contracts should be included in the agreements. This is crucial for the procedure as the changes that companies make plausibly could affect their relationship with the government authorities. The tax authorities should make periodic inspections. (Challoumis, The Keynesian Theory and the Theory of Cycle of Money 2018) Therefore the comparability analysis needs the periodic specification of contracts. This analysis is about the comparison of the indexed aims that the government puts with the real data which provides the enterprises. The arm's length principle procedure needs the periodic inspections of the companies which participate in controlled transactions ${ }^{1}$. The cost-sharing pends on the periodic check of companies which are tested parties. ${ }^{2}$ The companies of controlled transactions face taxation issues that are connected with their activities. (Zax 1988) Hence, the enterprises of controlled transactions should comply with the arm's length principle of the authorities. The comparability analysis has as a target to clarify the tax obligations of the companies they comply with the tax requirements of the authorities. (Boland 1991) Since the adequate agreement of the enterprises of controlled transactions is that which maximizes the costs in economic environments with a high tax rate and the same time maximizes their profits in tax environments with a low tax rate. Thence, the allocation of profits and losses clarifies the maximization of the utility of companies with controlled transaction activities.

Additionally, it should be mentioned that the enterprises of controlled transactions and tax authorities are proceeding to comparability analyses virtue to proportional adjustments. The proportional adjustments are a term that shows that the companies should adjust their data under conditions of lack of information. (King 2009) The companies of controlled transactions, many times when they don't have the adequate data to make comparisons with existing uncontrolled transactions of similar cases to perceive their condition, proportionally adjust their data. (Wilson 1986) Thereupon, the tested parties when obtaining that the profits and losses of companies from uncontrolled transactions are higher or lower than their profits and losses, they proceed to proportional analogies to be able to compare their data with data of uncontrolled transactions.

The production of goods is the reason for the profits and losses of the enterprises. (Challoumis, Arm's Length Principle and Fix Length Principle Mathematical Approach 2018) The same thing happens and for the services, where the profits and losses come from the services which offer to the companies of controlled transactions. Standing on the prior analysis:

\footnotetext{
${ }^{1}$ The arm's length principle provides the way that taxed the companies that proceed to international control transactions.

${ }^{2}$ Tested parties are the enterprises which participate in control transactions.

DOI: 10.25103/ijbesar.131.07 
$u=s(z f+\tilde{z} d)$

$z=|\tilde{z}-1|$

Where $u$ is about the impact factor of the comparability analysis. The symbol of $s$ is the amount of money using and the allocation of profits and losses. The symbol of $\mathrm{z}$ is a variable that receives values between 0 and 1 . The symbol of $f$ is about the cost that comes up from the production of goods, and the symbol of $d$ describes the cost of the distribution of the goods.

Using equations (1) to (2) determined the following equations:

$u_{c}=z f+\tilde{z} d$

And

$\mathrm{b}=\left(\mathrm{p}-u_{c}\right) * j_{1}$

The symbol of $b$ is the amount of taxes that should pay the companies of controlled transactions to the case of the arm's length principle. The symbol of $\mathrm{p}$ is the amount of money. The symbol of $u_{c}$ is the amount of tax obligations that can be avoided by the companies through the allocation of profits and losses. The symbol of $j_{1}$ is a variable for the rate of taxes. Then, equation (4) represents the case of the arm's length principle. Also, the case of the fixed length principle is described by the next equation:

$v=\mathrm{p}^{*} j_{2}$

The symbol of $v$ shows the taxes that should pay the companies that participate in controlled transactions, for the estimations of the fixed length principle. Then, $j_{2}$ is a coefficient for the rate of taxes in the case of fixed length principle. Thereupon, it is concluded according to the prior theory that:

$v \geq b$

From equations (4), (5) and (6) is obvious that to the case of fixed length principle the companies should pay more taxes, than to the case of the arm's length principle, as the authorities receive as a fact the condition that the international companies proceed to controlled transactions, to avoid to pay taxes.

The applied methodology is based on the Q.E. method. The Q.E. method is affiliated with the theory of axiomatics. (Challoumis, The Role of Risk to the International Controlled Transactions Years XXIII) The hypothesis is axiomatics. Then, the axiomatics is used to confirm the theoretical background and to confirm that the hypothesis complies with the results of the model. Thence, there are two facets of the axiomatics:

- If the results comply with the hypothesis, then the model is satisfied. In that case, the study stops as the model doesn't need any further examination.

- In the second case, if axiomatics is not satisfied, it should be made further analysis, until to have the adequate model.

Thence, the main concept of axiomatics stands in compliance with the hypothesis with the final results of the study. Forasmuch as is plausible with that way to clarify and modify the theory of the chosen model.

\section{The cycle of money and the ideal case of the cycle of money}

The tax revenues are lost savings from the economy, diminishing with that way the cycle of money. The lower taxes robust the cycle of money, as the small and medium economic units and enterprises can distribute the money again and again inside a country's economy, growing with that way the cycle of money, and reducing the lost money from the economy (enforced savings). The large companies which proceed to international controlled transactions achieve to avoid tax-paying, making the cycle of money weaker (escaped savings). For this reason, the companies of controlled transactions must pay higher taxes because otherwise a huge amount of money would be lost from a country's economy. To this work are used the following equations:

$\alpha=\alpha_{s}+\alpha_{t}$, or, $\frac{1}{v}+\alpha_{t}$ 


$$
\begin{aligned}
& x_{m}=m-a \\
& \mathrm{~m}=\mu+\alpha_{p} \\
& \mu=\sum_{\iota=0}^{n} \mu_{\iota} \\
& \alpha_{p}=\sum_{j=0}^{m} \alpha_{p j} \\
& c_{m}=\frac{d x_{m}}{d a} \\
& c_{\alpha}=\frac{d x_{m}}{d m} \\
& c_{y}=c_{m}-c_{\alpha}
\end{aligned}
$$

The symbol of $\alpha$ is the variable of the escaped savings, meaning the savings that lost from the consumption, as lost from a country's economy, as they are not saved to local banks, but they saved to international banks or are not taxed. The symbol of $\alpha_{s}$ is about the escaped savings of transfer pricing activities. The symbol of $\alpha_{t}$ is about the escaped savings by any other commercial activity. The symbol of $m$ is the financial liquidity in an economy. (OECD, Transfer Pricing Guidelines for Multinational Enterprises and Tax Administrations July 2017) The symbol of $\mu$ is about the consumption in an economy. The symbol of $\alpha_{p}$ is the enforcement savings of small-sized, medium-sized enterprises and the citizens. The symbol of $x_{m}$ is about the condition of financial liquidity in a country's economy. (Feinschreiber 2004) The symbol of $c_{m}$ is about the velocity of financial liquidity variations. The symbol of $c_{\alpha}$ is about the velocity of escaped savings. Then the symbol of $c_{y}$ is the cycle of money. Then, the cycle of money is a factor that determines the dynamic of an economy, meaning how well structured is an economy, noting how well distributed and reused many times the money inside the economy, without to be lost from it. Therefore, it is obtained that the cycle of money grows with the application of the fixed length principle and decreases to the case of the arm's length principle.

\section{The mathematical approach of the cycle of money with and without the impact factor of the education}

For the mathematical approach of the cycle of money used the prior equations:

$\alpha_{p}=\alpha_{r}+\alpha_{n} * h_{n}+\alpha_{m} * h_{m}$

And

$\alpha_{r} \geq \alpha_{n} * h_{n} \geq \alpha_{m} * h_{m}$

The symbol of $\alpha_{r}$ is about the impact factor for the rest of rewarding taxes. The variable of $\alpha_{n}$ symbolizes the impact factor of education and any technical knowledge. The factor of $\alpha_{m}$ is the impact factor of the health system. The factor of $h_{n}$, and of $h_{m}$, are accordingly the variables of the education and the health system impact. Therefore, using the prior equations is determined in the following table:

\begin{tabular}{|l|l|l|}
\hline Factors & Values & Values' \\
\hline$\alpha \mathrm{s}$ & 0.6 & 0.6 \\
$\alpha \mathrm{t}$ & 0.7 & 0.7 \\
$\mu$ & 0.9 & 0.9 \\
$\alpha \mathrm{r}$ & - & - \\
$\alpha_{\mathrm{n}} * \mathrm{~h}_{\mathrm{n}}$ & 0.3 & - \\
$\alpha_{\mathrm{m}} \mathrm{h}_{\mathrm{m}}$ & - & - \\
\hline
\end{tabular}

Table 1: Compiling coefficients (see Appendix II)

The prior factors have as an upper limit the value of 1 , and as a lower limit the value of o, but $S$ and $\tilde{S}$ could receive higher values than 1. After 461 repetitions extracted the next graph: 


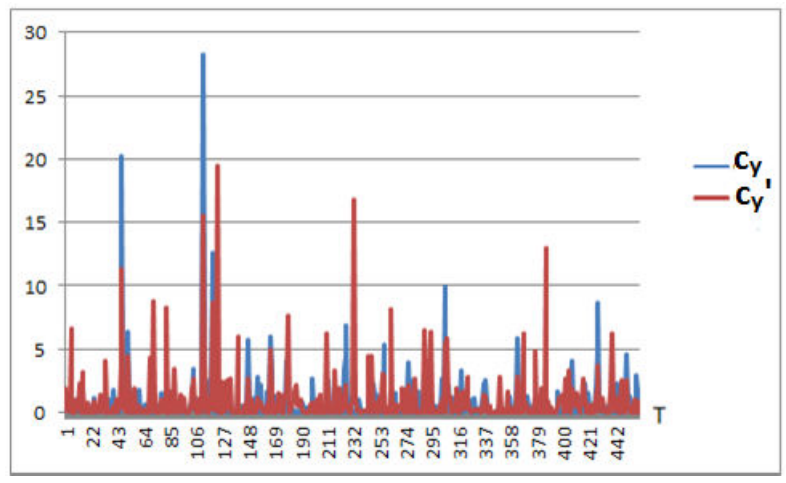

Figure 4: Comparison of the cycle of money with and without the impact factor of education

According to the prior scheme, it is obtained that the impact factor of education has an impact on the cycle of money (blue line). An economy with an appropriate education system has a declined cycle of money (red line) because the distribution of money is lower than the case that the cycle of money is higher (blue line). An economy with a low cycle of money would have lower savings and consumption as the high tax rates diminish the dynamic of the economy. To that case should apply higher taxes to larger companies because they save their money out of the country's economy.

\section{The case of the U.S. for the period of 2012-2017}

First, examine the relevant factors of education. This means that at this stage we determine the important factors of the model, standing on the theory. Therefore, is determined that:

\begin{tabular}{|l|l|l|l|l|}
\hline Year & GDP & Exports & Imports & Education \\
\hline 2012 & $15,155,255$ & $1,544,932$ & $2,274,462$ & 40,550 \\
2013 & $16,691,517$ & $1,577,587$ & $2,265,911$ & 39,852 \\
2014 & $17,427,609$ & $1,619,743$ & $2,410,855$ & 55,266 \\
2015 & $18,120,714$ & $1,501,846$ & $2,313,425$ & 88,014 \\
2016 & $18,624,475$ & $1,450,457$ & $2,248,209$ & 77,080 \\
2017 & $19,390,604$ & $2,407,390$ & $1,545,609$ & 115,367 \\
\hline p-value & $0.0520^{*}$ & $0.0467^{* *}$ & 0.4685 & dependent variable \\
p-value' & - & - & $0.0006 * * *$ & dependent variable \\
\hline
\end{tabular}

Table 2: Estimated variables (the amounts are in million dollars) (Education 2020) (OECD, Trend 2020)

To the prior table the three asterisks imply significant at 0.01 , the asterisks two asterisks imply significant at 0.5 , and the one asterisk imply significant at 0.1. From the prior table, it is received that the GDP is rejected the null hypothesis, therefore it is statistically significant. It is concluded that and the other variables are significant. The model is the following one:

$$
\begin{aligned}
& \text { Education }=\mathrm{f}(\mathrm{GDP}, \text { imports, exports }) \\
& \text { Education }=\beta_{0}+\beta_{1} \mathrm{GDP}+\beta_{2} \text { Imports }+\beta_{3} \text { Exports }+\varepsilon
\end{aligned}
$$

Thus, follows the clarification of the real case scenario according to the theory, with the most significant variable of the education, meaning the GDP as there is a direct connection between these two factors, according to the theory, the mathematical structure, the quantification approach, and the econometric data.

It follows an example of the case of the U.S. using data from the WITS and the U.S. Department of education. It is made a comparison between two different periods. Are used two elements because these are the explaining factors. The trend between them is proven through the work of OECD. Then, for the explaining variables of U.S.:

1. Education spending $=40,550$ US million dollars, for 2012 (initially)

2. Education spending $=115,367$ US million dollars for 2017 (finally)

3. $\mathrm{GDP}=15,155,255$ US million dollars for 2012 (initially)

4. $\mathrm{GDP}=19,390,604$ US million dollars for 2017 (finally) 
According to OECD even in the recent economic downturn, the tertiary graduates generated a positive impact on GDP of more than half a percentage point per year, from 2008 to 2010. The education and the GDP are directly connected. Therefore, from equations (7) to (16) received:

$c_{m}=\frac{d x_{m}}{d a} \cong$ GDP (includes at least four factors, like exports, investments, imports, consumption etc.)

$\mathrm{da}=\mathrm{a}$, for one period

$d x_{m}=x_{m}$, for one period

$c_{\alpha}=\frac{d x_{m}}{d m}$

$c_{y}=c_{m}$

Then, $c_{y}=\mathrm{f}(\alpha \mathrm{n} * \mathrm{hn})$, or, $c_{y}=\mathrm{f}$ (Education)

From the prior data, and equations follows the next table:

\begin{tabular}{lll}
\hline Factors & Values(dollars/capita, 2012) & Values'(dollars/capita, for 2017) \\
\hline$c_{m}, c_{y}$ & 46,318 & 59,262 \\
$\alpha \mathrm{n}^{*} \mathrm{hn}$ & 123.93 & 422.28 (it is 0.3 in the Q.E. approach of table 1) \\
\hline
\end{tabular}

Table 3: Application of real explaining values to the extracted model

According to the prior table, received the next graphs:
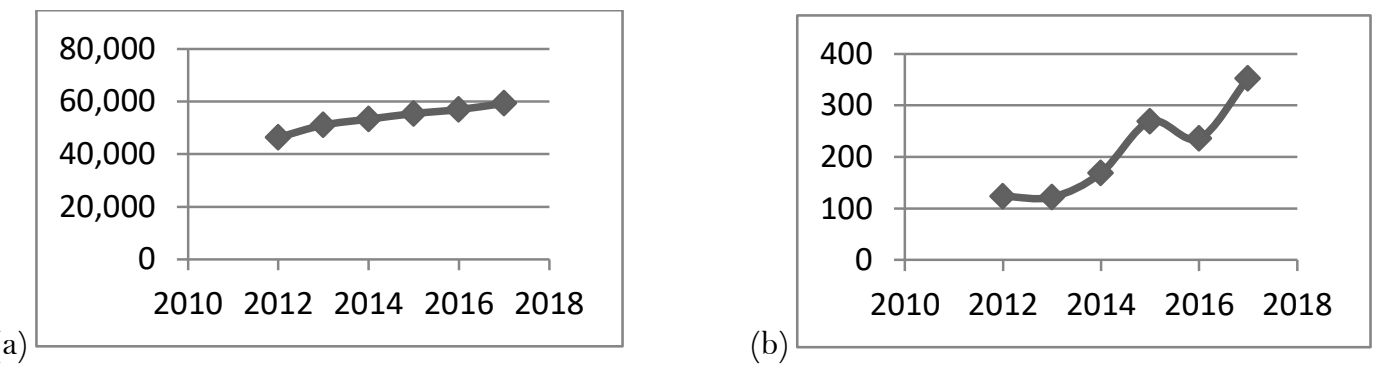

Figure 5: (a) GDP/capita diagram of U.S. (OECD, Gross domestic product (GDP) (indicator) 2019) (b) Education/capita spending diagram of the U.S. (Research 2019)

It is obtained that the quantification results comply with the real case of the U.S. paradigm. The graph of education expenditures follows the GDP, as expected from the results of the quantified model. It is clarified from figures 4 and 5 that education increases the cycle of money of the U.S., and contemporaneously the quantified model has the same result with the real case scenario of the U.S. paradigm.

\section{Conclusions}

The general estimations of the education system, with programming and compiling, are used to define the adequacy of the applied mathematical model. Then the hypothesis that the taxes for the education system robust the economy complies. The case of U.S. taxes for the education system is used as a real case scenario of the already confirmed model by programming. The case of the U.S. is reconfirmed by an econometrical application. Then, the hypothesis that taxes of the education system robust the economy is confirmed with be mathematical and theoretical clarification, by programming and completion procedure and finally by the econometric application. Then to this paper showed the relation of the dynamic of the economy using the cycle of money with the public sector and the international controlled transactions. It is obtained using R.B.Q. model, as expected, that an economy with the avoidance of education has a lower economic dynamic and on the other hand, an economy with the presence of the appropriate educations system has a higher economic dynamic. The taxes of the economy do not return to the market. Thence, the investments and the consumption of this economy would be lower. This means that as the most taxes harm the economy, on the other hand, the education taxes have a positive effect on the economy, as they return to the economy, to be used for consumption and investments. This is the main difference between general taxes and the three rewarding taxes (education taxes, health taxes, and reststructural taxes. This analysis showed that the taxes for the education system help the economy. It is perceived that the economies which estimate education receive more utility than to the case that there does not be a proper education DOI: 10.25103/ijbesar.131.07 
system. The education system advances the dynamic of the economy complying with the theory of the cycle of money. Future research could be achieved for a different case scenario, with a three steps methodology of the R.B.Q. the method, meaning the theoretical/mathematical study, the programming/compilation application, and the econometric application of the model, showing that to all cases the result is the same and is plausible to exclude general results.

\section{Appendix I}

Following the R.B.Q. model, the applied steps are these:

Step I: Determination of the theoretical background and the mathematical structure.

Step II: Application of the Q.E. method, meaning the quantification procedure.

Step III: Econometric analysis and behavioral study of a real case scenario.

\section{Appendix II}

Code of the Q.E. method, about the quantification of the model:

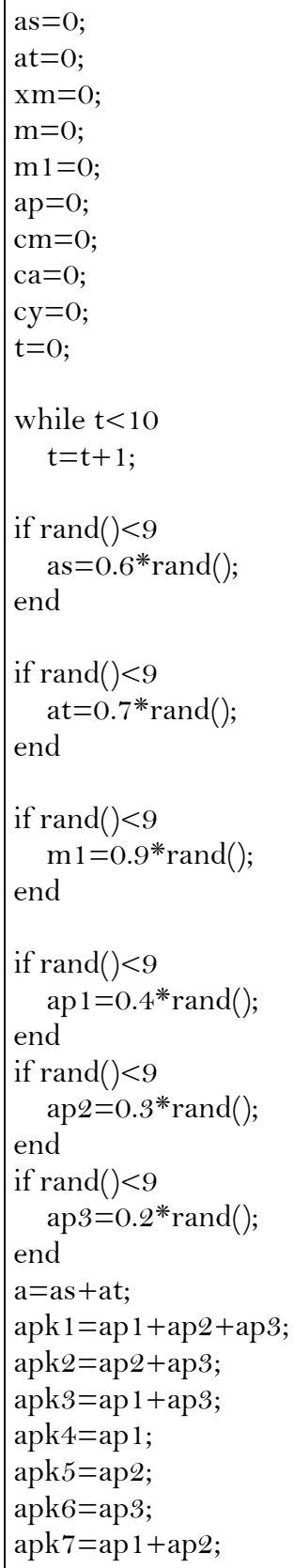




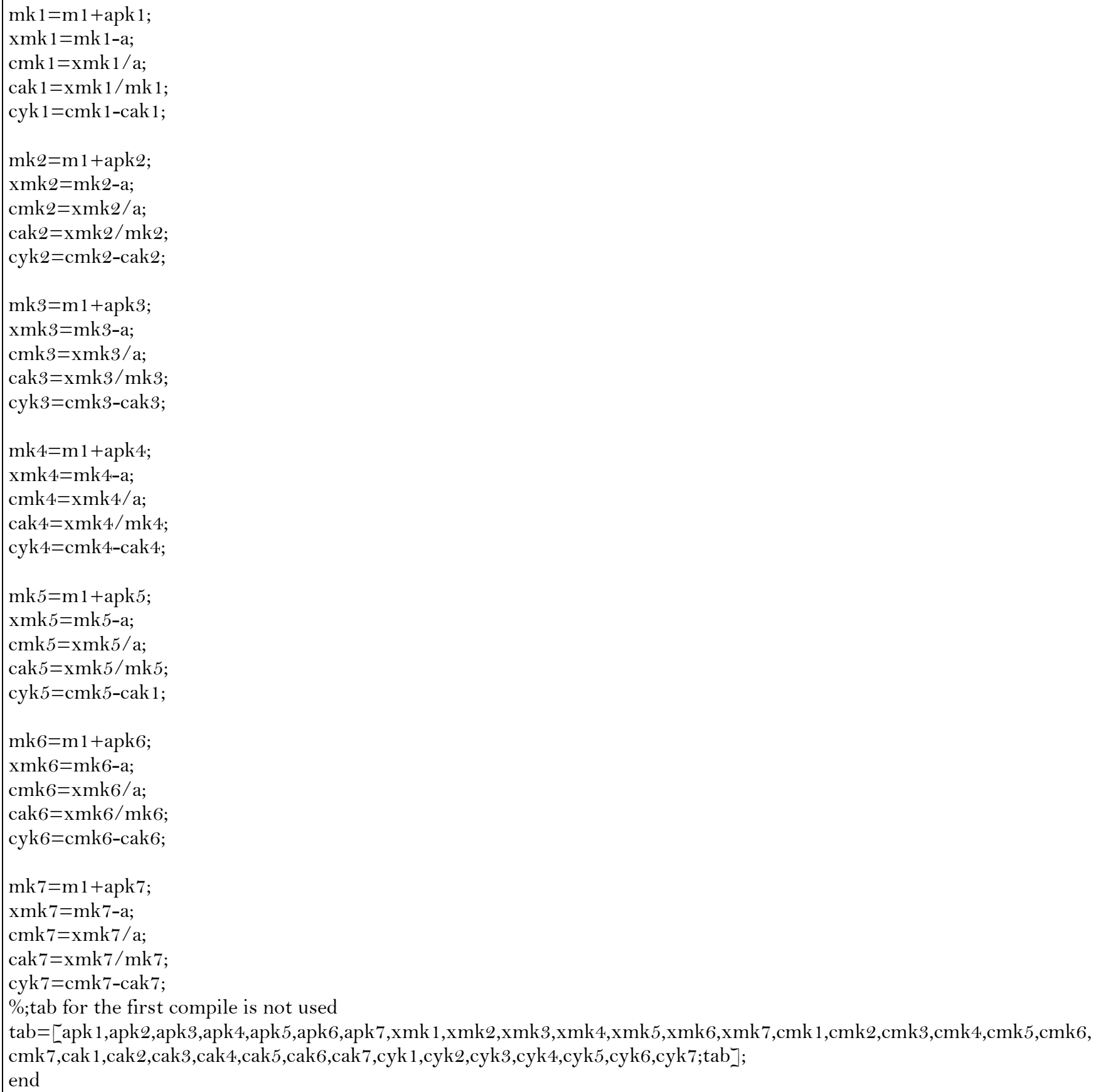

\section{References}

Asonitou S, Mandilas A., Chytis E., Latsou D. (2018). A Greek Evaluation Of The Course Experience Questionnaire: Students' Conceptions Of The Teaching Quality Of Higher Education Accounting Studies IJBESAR (International Journal of Business and Economic Sciences Applied Research), 11(2), 5 1-62.

Boland L. A. (1991). The Methodology of Economic Model Building. London and New York: Routledge.

Camerer, C. F. (2003). The behavioral challenge to economics: Understanding normal people. Federal Reserve of Boston meeting "How Humans Behave", Caltech, Pasadena CA 91125, 1-34.

Challoumis C. (2018) "Arm's Length Principle and Fix Length Principle Mathematical Approach." SSRN. March 23, 2018. Challoumis, Constantinos, Arm's Length Principle and Fix Length Principle Mathematical Approach. Available at SSRN: https://ssrn.com/abstract=3148276 or http://dx.doi.org/10.2139/ssrn.3148276. 
Challoumis C. (2015) "Fuzzy Logic Concepts in Economics." SSRN. June 4, 2018. Challoumis, Constantinos, Fuzzy Logic Concepts in Economics. Available at SSRN: https://ssrn.com/abstract=3185732 or http://dx.doi.org/10.2 139/ssrn.3185732.

Challoumis C. (2018)"Methods of Controlled Transactions and the Behavior of Companies According to the Public and Tax Policy." ECONOMICS, De Gruyter, Sciendo (ECONOMICS, 6(1), 33-43. DOI: https://doi.org/10.2478/eoik-2018-0003) 6(1), no. ECONOMICS, 6(1), 33-43. DOI: https://doi.org/10.2478/eoik-2018-0003 (2018): 33-43.

Challoumis C. (2017). "Quantification of Everything (A Methodology for Quantification of Quality Data with Application and to Social and Theoretical Sciences)." SSRN.

Challoumis, Constantinos. 2019. "The R.B.Q. (Rational, Behavioral and Quantified) Model." Economics 98 (1): 6-18. https://doi.org/10.15388/ekon.2019.1.1.

Challoumis, Constantinos. "The Keynesian Theory and the Theory of Cycle of Money." Hyperion, 2018: https://hej.hyperion.ro/articles/3(6)_2018/HEJ\%20nr3(6)_2018_A1Challoumis.pdf.

Challoumis C. (2019). The R.B.Q. (Rational, "Behavioral and Quantified) model", Ekonomika, 98 (1).

Challoumis, Constantinos. "The Theory of Cycle of Money." SSRN, 2018: https://ssrn.com/abstract=3149156 or http://dx.doi.org/10.2139/ssrn.3149156.

Challoumis (2018) "The Role of Risk to the International Controlled Transactions." (Annals of "Dunarea de Jos" University of Galati Fascicle I. Economics and Applied Informatics) no2/2018, no. ISSN-Online 2344-441X.

Chiang, A. A. (2005). Fundamental Methods of Mathematical Economics. McGraw-Hill(0-07-010813-7).

Crocco, M. (1998). Investment Decision and methodology: Keynes and Neoclassical. Est. Econ., Sao Paolo, 28(2), $283-315$.

Feinschreiber R. (2004). Transfer pricing Methods An Application Guide. new Jersey: John Wiley\&Sons.

Foundation for Economic and Industrial Research (data). 2019. Education in U.S.: Crisis and Development of Public and Private Expenditures, FEIR, p.83. http://iobe.gr/docs/research/RES_05_F_14032019_REP.pdf.

Gihman, J., \& Skorohod, A. V. (1972). Stochastic Differential Equations. Springer-Vertang inc. New York.

Gihman, J., \& Skorohod, A. V. (1974). The theory of Stochastic Processes. Springer-Vertag Inc. New York.

Gihman, J., \& Skorohod, A. V. (1975). The theory of Stochastic Processes. Springer-Vertang, 1.

King Elizabeth (2009) "transfer pricing and corporate taxation problems, Practical Implications and Proposed Solutions." Springer.

Meier B. D. (2000), and D. T. Rosenbaum. "Making single mothers work: Recent tax and welfare policy and its effects." (National Tax Journal) $53(4)$.

OECD (data). July 2017. Transfer Pricing Guidelines for Multinational Enterprises and Tax Administrations. Paris: OECD Publishing. OECD (data). 2001. Transfer Pricing Guidelines for Multinational Enterprises and Tax Administrations. Paris: OECD.

OECD (data). 2020. Trend. https://www.oecd-ilibrary.org/docserver/eag_highlights-2012-15en.pdf? expires $=1556715212 \& \mathrm{id}=\mathrm{id} \&$ accname $=$ guest\&checksum $=$ oEFAA6AF2 172417614D9616D1DB3 10C8, https://doi.org/10.1787/eag_highlights-2012-15-en.

OECD (2017) Transfer Pricing Guidelines for Multinational Enterprises and Tax Administrations. Paris: OECD Publishing.

OECD (2001). Transfer Pricing Guidelines for Multinational Enterprises and Tax Administrations. Paris: OECD.

U.S. Departement of Education (data). 2020. Data: https://www2.ed.gov/about/overview/budget/history/index.html

United Nations. Practical Manual on Transfer Pricing for Developing Countries. New York: United Nations Department of Economic \& Social Affairs, 2013.

Wilson, J. D. "A theory of interregional tax competition journal of Urban Economics." 19 (3) pp.296-315 (1986).

Zax, J. S. (1988) "Fringe benefits, income tax exemptions, and implicit subsidies." Journal of Public Economics 171-183.

This is an Open Access article distributed under the terms of the Creative Commons Attribution License

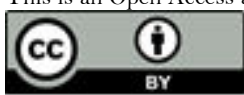

